Research article

\title{
Some ethnomedicinal plants used against high blood pressure in Bargarh district in Western Odisha (India)
}

\author{
S. K. Sen ${ }^{1 *}$ and L. M. Behera ${ }^{2}$ \\ ${ }^{1}$ Department of Botany, Panchayat College, Bargarh - 768028, India \\ ${ }^{2}$ Ex-Reader in Botany, Modipara (Near Water Tank), Sambalpur - 768002, India \\ *Corresponding Author: sunilsen06@rediffmail.com \\ [Accepted: 20 September 2016]
}

\begin{abstract}
The knowledge and usage of herbal medicine for the treatment of various ailments among the rural people still a major part of their life and culture. An ethnomedicinal survey was conducted during 2010-13 in different forest pockets and rural areas to collect ethnobotanical information on plant species from the local inhabitants of Bargarh district. Out of a number of collected plant species some are reported to be very useful against high blood pressure. The outcome of this survey is that the local people of the study area still have a strong faith in the efficacy and success of the herbal medicine.
\end{abstract}

Keywords: Ethnomedicine - High blood pressure - Tribals - Bargarh district.

[Cite as: Sen SK \& Behera LM (2016) Some ethnomedicinal plants used against high blood pressure in Bargarh district in Western Odisha (India). Tropical Plant Research 3(3): 517-521]

\section{INTRODUCTION}

Medicinal plants have been used since time immemorial for the treatment of human as well as animal diseases and ailments. Traditional medicine practice is an important part of health care delivery in moist of the developing countries (Akerel 1998, Truyen et al. 2105, Ngbolua et al. 2016). According to World Health Organization, approximately $80 \%$ population in developing countries depends on traditional medicine for the primary healthcare (Mehra et al. 2014). A major portion of these involves the use of medicinal plants. Use of medicinal plants are known by ethnic tribes who resides in the forest area pay a vital role in using forest vegetation of food, cloth, shelter, for the treatment of common ailments, utilize the plants and manage to conserve it to some extent for future use.

Odisha State is situated in the eastern part of India having 30 districts. Bargarh is one among them located in western part of Odisha. Prior to $5^{\text {th }}$ November 2011, Bargarh was a subdivision under the district Sambalpur. The district lies between $20^{\circ} 40^{\prime}-21^{\circ} 49^{\prime} \mathrm{N}$ and $82^{\circ} 45^{\prime}-83^{\circ} 48^{\prime} \mathrm{E}$. The District is surrounded by Chhattisgarh state on the north, Sambalpur District on the east, Bolangir and Subarnapur on the south and Nuapada District on the west. The Bargarh district experiences extreme type of climate with hot and dry summer followed by humid monsoon and chilling winter. The temperature varies between $10^{\circ} \mathrm{C}$ to $46^{\circ} \mathrm{C}$. The average annual rainfall in the district is $1527 \mathrm{~mm}$.

The tribals such as Sahanra (Soara), Binjhal, Gond, Kondh, Munda, Kuli, Kalanga, Oran, Mirdha, Dharua, Kisan, Kharia and Parja are inhabited in the Bargarh district. The tribals mostly dependent on their traditional healing system for healthcare and for treating various diseases (Bajpai et al. 2016). Tradition and beliefs are the only basis of use of the herbal medicine. During the ethnobotanical survey in the district, it has been observed that many plants species are being used by the tribals and other rural people for various purposes including herbal medicine to cure and or preventive diseases. Generally the plant parts such as root, leaf, bark, stem, flower, fruit, gum and resin are used as paste, powder, extract, decoction etc. by the people to cure diseases and ailments (Deepa et al. 2016).

Some valuable research works have been contributed in the last four to five decades from this locality (Panigrahi 1963, Brahmam \& Saxena 1990, Misra et al. 1994, Misra 2004, Pradhan et al. 1999, Sen \& Pradhan 1999, Behera \& Sen 2007, 2008, Sen \& Behera 2003, 2008). But no work on the present subject so far has been contributed from the study area. Therefore, an attempt has been made in this paper to highlights on some ethnomedicinal plants used for the treatment of high blood pressure in Bargarh district. 


\section{MATERIALS AND METHODS}

Field trips were conducted to different forest and rural area of Bargarh district during 2010-2013. The local traditional healers, herbal medicine practitioners, village headman, experienced old men and women were contacted and interviewed to record the ethnomedicinal uses of the plants and their local names (Bajpai et al. 2016). Mostly collections were made from local forests, scrub jungle, village suburbs and cultivated fields. Repeated quarries were made to confirm the authenticity of the information gathered from the local inhabitants. He collected plant specimens were identified with the help of flora books (Haines 1921-25, Saxena \& Brahmam 1994-96). The latest botanical nomenclature has been checked with the world renowned and widely accepted website http://www.the plantlist.org. (The Plant List 2010). The herbarium specimens have been deposited in the herbarium of Botany Department, Panchayat College, Bargarh, Odisha.

\section{RESULTS}

Enumeration of species

In the enumeration, the names of 10 plant species by the ethnic people of Bargarh district for the treatment of high blood pressure have been arranged alphabetically along with their correct botanical name, family in parenthesis, local names in inverted comma, locality and collection number, parts used, mode of preparation, details of ethnomedicinal uses.

1. Allium sativum L. (Amaryllidaceae), 'Lesun', Udepali-529 (Fig. 1A)

$2-3$ cloves of bulb are soaked in water overnight and either it is swallowed or crushed to paste is taken with a little warm water once daily in empty stomach in the morning. Fresh leaf paste $(5-10 \mathrm{~g})$ is taken once daily in empty stomach in the morning.

2. Catharanthus roseus (L.) G. Don (Apocynaceae), 'Baramasi', Beherapali-234 (Fig. 1B) Petals (5 numbers) are chewed once in the morning in empty stomach.

3. Cuscuta reflexa Roxb. (Convolvulaceae), 'Nirmuli', Khandijharan-276 (Fig. 1C) Whole plant juice ( 2 teaspoonful) is taken once daily in stomach in the morning.

4. Hygrophila auriculata (Schumach.) Heine, (Acanthaceae), 'Kuilekha', Ramkhol-534 (Fig. 1D) Leaf juice (1 teaspoon) and Piper nigrum fruit (5-7 in number) powder are mixed together and taken once daily in empty stomach for 15 days to get relief from high blood pressure at least for a period of one year.

5. Moringa oleifera Lam. (Moringaceae), 'Munga', Ramkhol-256 (Fig. 1E)

Leaf juice (one teaspoonful) is taken once daily in empty stomach for one month to get relief from hypertension at least for period of one year. Tender leaves are chewed early in the morning for one month to cure blood pressure for one year.

6. Psydrax dicoccos Gaertn. (Rubiaceae), 'Benimanj', Ramkhol-376 (Fig. 1F)

Equal amount of leaf and bark are crushed together and the juice $(5 \mathrm{ml})$ is taken 1-2 times daily in empty stomach.

7. Rauvolfia serpentina (L.) Benth. ex Kurz (Apocynaceae), 'Patalgarud', Nrusinghnath- 519 (Fig. 1G)

Root powder/ paste (1.0-1.5 g) is given once daily regularly 15 days and after three days break once again the medicine is continue for 15 days.

8. Senna occidentalis (L.) Link. (Caesalpiniaceae), 'Chakunda', Kharmunda-217 (Fig. 1H)

Fresh leaf paste $(5-10 \mathrm{~g})$ is taken once daily in empty stomach in the morning.

9. Terminalia arjuna (Roxb. ex DC.) Wt. \& Arn. (Combretaceae), 'Ka', Khandijharan-316 (Fig. 1I)

Bark $(10 \mathrm{~g})$ is boiled in a glass $(250 \mathrm{ml})$ of water to obtain $1 / 4$ decoction is taken once daily in empty stomach early in the morning for one month. Bark powder $(50 \mathrm{gm})$ and old jaggery $(50 \mathrm{gm})$ are mixed together and made into pills of $1 \mathrm{~cm}$ size. One pill is taken once daily in warm water.

10. Trigonella foenum-graecum L. (Fabaceae), Methi, Beherapali-236 (Fig. 1J)

Seed powder $(5 \mathrm{~g})$ is taken with warm water in empty stomach once daily.

\section{DISCUSSION}

The present study focuses on traditional medicines used by the tribals to cure or get relief from high blood pressure. Ten plant species from 9 families have been identified with 13 ethnomedicinal prescriptions used by the tribals of the present study. The observation revealed that the herbal medicines used by the tribals are mostly www.tropicalplantresearch.com 

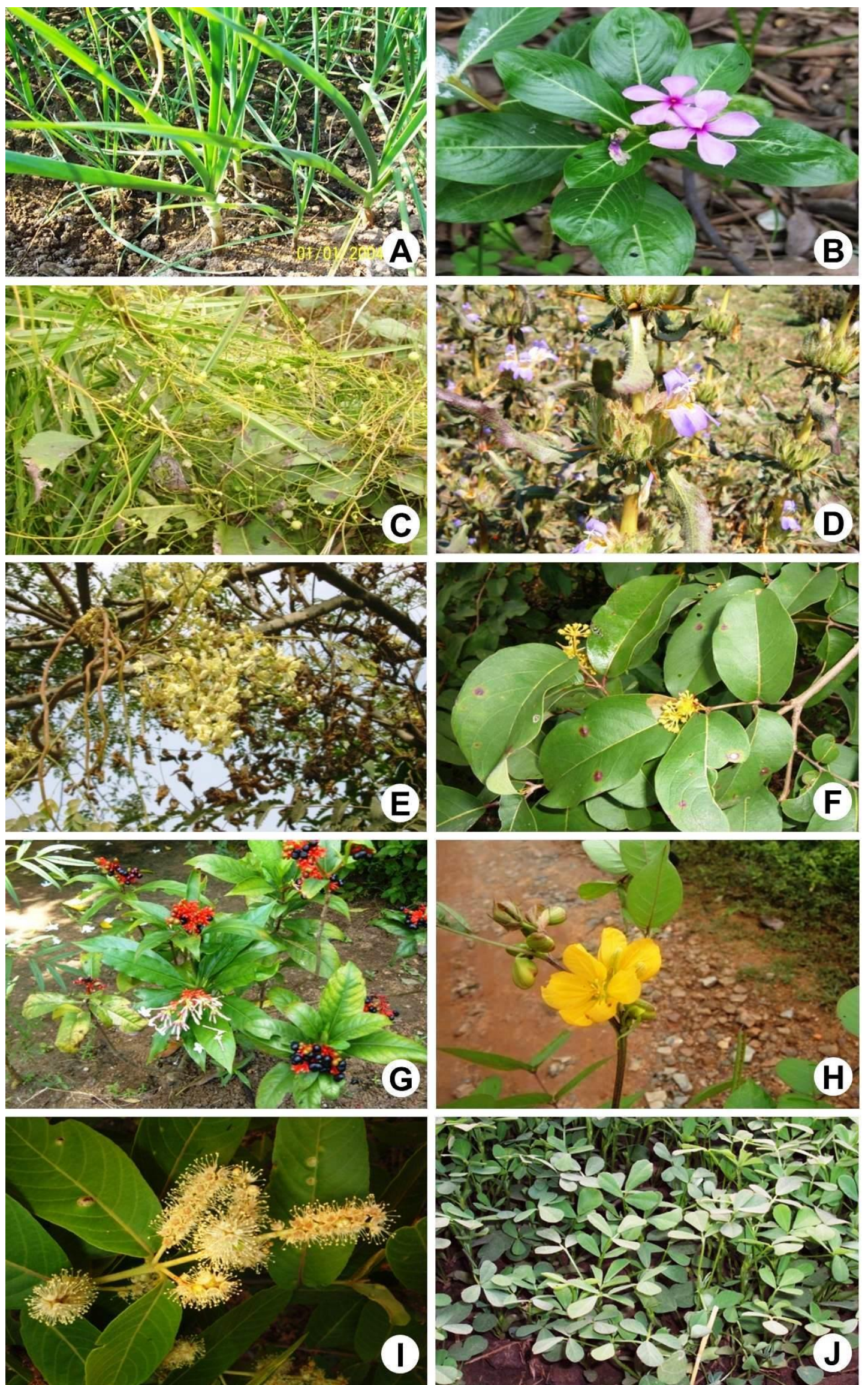

Figure 1. Plants used by the ethnic people for the treatment of high blood pressure: A, Allium sativum; B, Catharanthus roseus; C, Cuscuta reflexa; D, Hygrophila auriculata; $\mathbf{E}$, Moringa oleifera; $\mathbf{F}$, Psydrax dicoccos; $\mathbf{G}$, Rauvolfia serpentina; $\mathbf{H}$, Senna occidentalis; I, Terminalia arjuna; J, Trigonella foenum-graecum. 
administered in the form of paste, powder, juice, decoction, prepared in a crude method from different plant parts such as of root, bulb, bark, leaves, flower, seed and whole plant. Of the various plant parts used, the leaves were most commonly used. Leaf is used maximum (4 prescriptions), followed by bark ( 3 prescriptions), root ( 2 prescriptions)and other plant parts are used once in each case and in one case both leaf and bark are used in one prescription (Fig. 2).

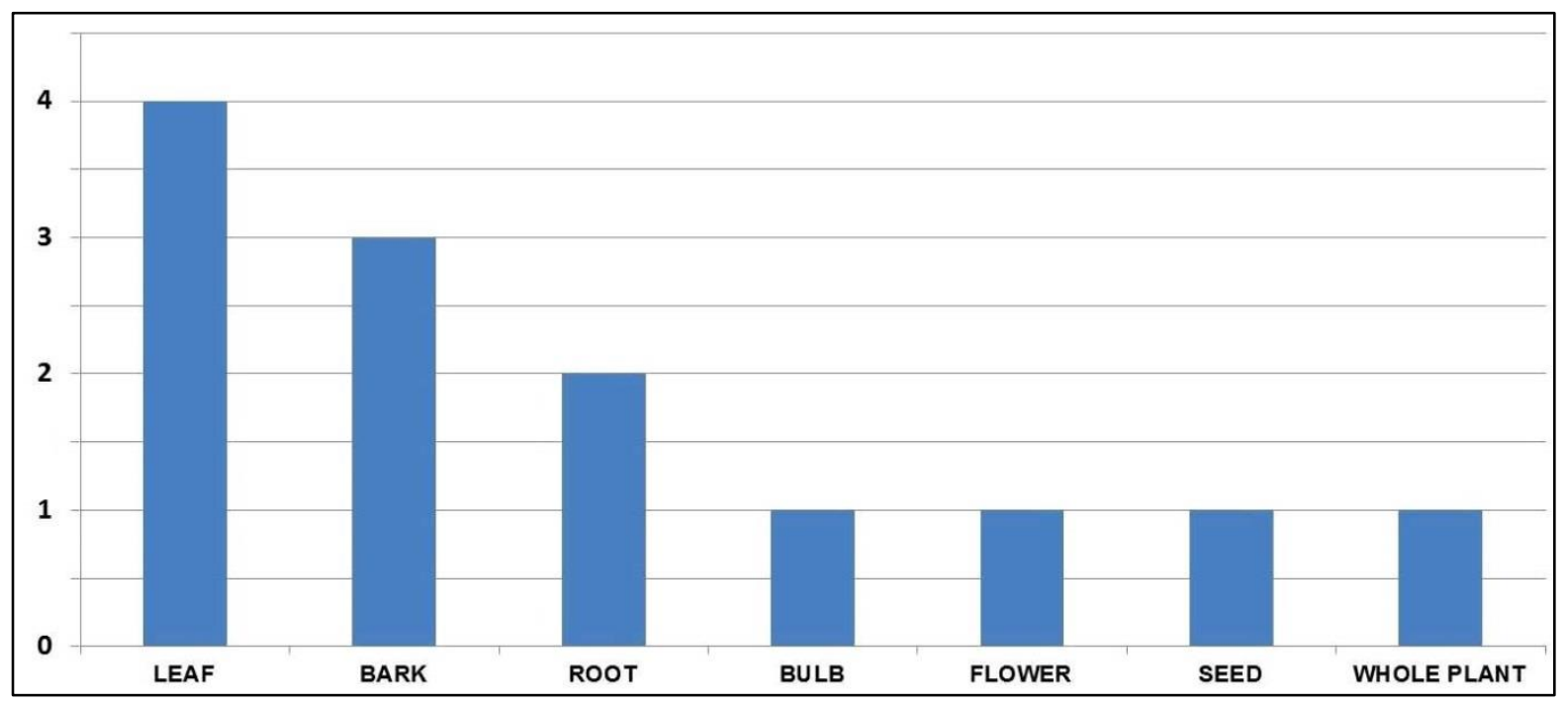

Figure 2. Plant parts used in the treatment high blood pressure.

It has also been highlighted that after observing their mode of treatment by different herbal medicine practitioners, which are compared with some of the scientific literatures (Jain 1991, Kirtikar \& Basu 1991, Chopra et al. 1992, Ambasta et al. 1992, Warrier 1996, Pal \& Jain 1998, Joshi 2004, Paria 2005, Singh 2013) and it has been recorded that out of 13 prescriptions 7 from 6 plant species (with asterisk mark) are new report.

\section{CONCLUSION}

The tribals depend on the plants around them which made them acquire knowledge of economic medicinal properties of many plants by trial and error. Consequently, they act as knowledge saviour for the utilization of many useful plants accumulated and enriched through generations and passed to one another without any written documents. But careful approaches should be followed before administration these drugs. The lack of proper documentation and carelessness towards the knowledge of ethnomedicine are forcing depletion of the traditional knowledge, which has to be preserved for the future benefit of the human civilization. Proper documentation and digitalization of tribal information is utmost importance. However, the present study may create some awareness among the people which might help to conserve their rich and effective ethnomedicinal knowledge in this region.

\section{ACKNOWLEDGEMENTS}

Authors are thankful to Prof N. B. Pradhan, Retired Reader in Botany and Mr. Pareswar Sahu for their kind help during field collection and identification of plant materials. Authors are also thankful to the local informants for sharing their valuable ethnomedicinal knowledge about the plants.

\section{REFERENCES}

Akerel O (1998) Medicinal plants and primary health care agenda for action. Fitoterapia 59: 355-363.

Ambasta SP, Ram Chandran K, Kashyappa K \& Chand R (1992) Useful plants of India. Publication and Information Directorate, CSIR, New Delhi, 918 p.

Bajpai O, Pandey J \& Chaudhary LB (2016) Ethnomedicinal uses of tree species by Tharu tribes in the Himalayan Terai region of India. Research Journal of Medicinal Plant 10(1): 19-41.

Behera LM \& Sen SK (2007) Traditional use of some plants against gynecological disorders by the tribals Ramkhol village forest of Barapahad hill range. Advances in Plant Sciences 20 (2): 555-557.

Behera LM \& Sen SK (2008) Ethnobotnay of Western Orissa, India. In: Patil DA (eds) Herbal cures: Traditional Approach. Aavishkar Publishers, Distributors, Jaipur, India, pp. 316-331. 
Brahmam M \& Saxena HO (1990) Ethnobotany of Gandhamardan Hills - Some noteworthy folk-medicinal uses. Ethnobotany 2: 71-79.

Chopra RN, Nayar SL \& Chopra IR (1996) Glossary of Indian Medicinal Plants (Reprint edition). National Institute of Science Communication, CSIR, New Delhi, $330 \mathrm{p}$.

Deepa MR, Sharma Dharampal P \& Udayan PS (2016) Floristic diversities and medicinal importance of selected sacred groves in Thrissur district, Kerala. Tropical Plant Research 3(1): 230-242.

Haines HH (1921-25) The Botany of Bihar and Orissa. Arnold \& Son \&West Nirman Ltd., London, 1348 p.

Jain SK (1991) Dictionary of Indian Folk Medicine and Ethnobotany. Deep Publications, New Delhi, 311 p.

Joshi SG (2006) Medicinal Plants (Reprint edition). Oxford and IBH publishing Co. Pvt. Ltd., New Delhi, 419 p.

Kirtikar KR \& Basu BD (1991) Indian Medicinal Plants (Reprint edition). Lalit Mohan Basu, Allahabad.

Mehra A, Bajpai O \& Joshi H (2014) Diversity, utilization and sacred values of Ethno- medicinal plants of Kumaun Himalaya. Tropical Plant Research 1(3): 80-86.

Mishra RC (1994) Studies on the flora and remote sensing of natural resources of Nrusinghnath-Harishankar Complex, Orissa, Ph.D. thesis. Berhampur University, Orissa, India.

Mishra RC, Panda PC \& Das P (1994) Lesser known medicinal uses of plants among the tribals of Gandhamardan hill range, Orissa. Higher plants of Indian subcontinent (Additional Series of Indian Journal of Forestry No.VI) 3: 135-142.

Ngbolua KN, Mihigo SO, Liyongo CI, Ashande MC, Tshibangu DST, Zoawe BG, Baholy R, Fatiany PR \& Mpiana PT (2016) Ethno-botanical survey of plant species used in traditional medicine in Kinshasa city (Democratic Republic of the Congo). Tropical Plant Research 3(2): 413-427.

Pal DC \& Jain SK (1998) Tribal Medicine. NayaProkash, Calcutta, 317 p.

Panigrahi G (1963) Gandhamardan Parbat, Orissa-A potential source of important indigenous drugs. Bulletin of Regional Research Laboratory, Јатти 1: 111-116.

Paria ND (2005) Medicinal Plant Resources of South West Bengal. Directorate of forest, Govt. of West Bengal, Kolkata, 198 p.

Pradhan NB, Pradhan RN, Sen SK \&Sahu P (1999) Some threatened noteworthy medicinal plants of Bargarh district (Orissa). Neo Botanica 7: 97-100.

Saxena HO \& Brahmam M (1994-96) The Flora of Orissa. Regional Research Laboratory, Orissa and Orissa Forest Development Corporation Ltd., Orissa, 2918 p.

Sen K Sen \& Behera LM (2008) Ethnomedicinal plants used by the tribals of Bargarh district to cure diarrhoea and dysentery. Indian Journal Traditional Knowledge 7(3): 425-428.

Sen SK \& Behera LM (2003) Ethnomedicinal plants used against skin diseases at Bargarh district in Orissa (India). Ethnobotany 15 (1\&2): 90-96.

Sen SK \& Pradhan NB (1999) Conservation of ethnomedicinal plants of Bargarh district in Orissa. Advances in Plant Sciences 12: 207-213.

Singh H (2013) Ethnomedicinal uses of some wild flowers in Sundargarh, Mayurbhanj, Angul and Bolangir districts of Odisha. Ethnobotany 25: 115-119.

The Plant List (2010) The Plant List: A working list of all plant species. Available from: http://www.the plantlist.org. (accessed: 03 Apr. 2016).

Truyen DM, Mansor M \& Ruddin AS (2015) A note on Aroids Ethnobotany in Hau River, Vietnam. Tropical Plant Research 2(1): 58-63.

Warrier PK, Nambir VPK \& Ramankutty G (1996) Indian Medicinal Plants (5 vols). Orient Logman, New Delhi. 